\title{
The Disaster Mitigation of Slow-Landslide Movement Induced By Rainfall Based on Ps-Insar Method
}

\author{
Farid Nur Bahti ${ }^{1}$, Atika Praptawati ${ }^{2}$ \\ ${ }^{1}$ Disaster amd Environment Monitoring (DEMon) Lab, National Central University, Taiwan \\ ${ }^{2}$ Geotechnical Centrifuge Lab, National Central Univeristy, Taiwan
}

\begin{abstract}
Disaster management is a big issue in the past few years. Talking about the disaster, an aspect that should be focussed on is mitigation. The development and the ability of Remote sensing technology have a significant impact on disaster management and significantly contribute to disaster mitigation, such as for the disaster monitoring system. The slowlandslide movement is rarely considered in disaster mitigation, even though the acceleration can increase time by time and will be more dangerous than usual. Therefore, the observation of the remote sensing technology is needed for disaster mitigation. PS-InSAR as a spacebased observation method can observe the continuous movement on a site location. Thus, this study illustrates the slow-landslide movement mechanism based on remote sensing technology using the PS-InSAR method compared with rainfall data. In this study, the Sentinel-1 images and STAMPS/MTI by Hooper (2004) successfully detect the displacement rate of the Kalibawang Village, Special Region of Yogyakarta, Indonesia, with the maximum displacement rate $-23 \mathrm{~mm}$ /year along the Line of Sight (LoS) of the satellite. The PS-InSAR result was also compared with the rainfall data, and shows a correlation of the movement during the rainfall season. Therefore, further mitigation is needed to reduce the risk of the disaster.
\end{abstract}

\section{CONTACT}

faridnurbahti01@gmail.com

\section{KEYWORDS}

Disaster, Landslide, Slow-

Landslide, PS-InSAR,

STAMPS/ MTI.

\section{INTRODUCTION}

As a tropical country, Indonesia has two main seasons: the rainy and the dry. Seasonal variations have a substantial impact on natural phenomena. Commonly, a landslide is beginning during wet seasons. The constant rain is like a warning phenomenon, especially when it falls on a slope with high permeability soil or in a mountainous area. However, many other variables, such as geological aspects, geomorphology, Etc., contributed to the land movement. [1-3].

It is a challenge for risk management or disaster mitigation regarding the landslide due to many uncertain things. On the other side, it is essential to protect the human population in the location. The comprehensive studying for slope failure mechanism has been widely studied in this past decade. The various mechanism has widely explained landslide, especially concerning landslide triggered by rainfall [4].

The location interest is in the Kalibawang village, located on the Kulonprogo Regency, West of Yogyakarta, Indonesia, as shown in Figure 1. The study location is located around a mountainous area and a bit hilly. Landslide is a big issue in this location. During 2017, the movement affected some public facilities, like the school and the irrigation tunnel at the site location. [5]. A previous study about land movement in Kalibawang mentioned by [6] studied the landslide hazard map of the Kalibawang village. The result was shown if the Kalibawang village has the possibility of land movement due to several places with a high risk of landslide (see Figure 2).

The monitoring system based on remote sensing technology has been widely used in this era, such as using the PS-InSAR method, which uses the SAR image to monitor the movement on an area. The study aims to know the landslide mechanism on the location interest regarding what has been mentioned before. Here, we adjust the rainfall as a variable that caused the movement. Hence, we will use the rainfall data and the PS-InSAR result to find the correlation of both data.

\section{Interferogram SAR}

Concerning landslide disaster mitigation, the investigation of the site location is essential to minimizing the risk. Thus, it is needed to monitor pre-failure motions and their progression through time and examine the predisposing and triggering elements [7, 8]. Since the Seasat satellite was launched in 1972, many techniques were developed for monitoring the earth's surface. The Seasat satellite is a kind of active sensor satellite, which can monitor the earth's surface without the distraction of the environment due to the image captured using the radar. 


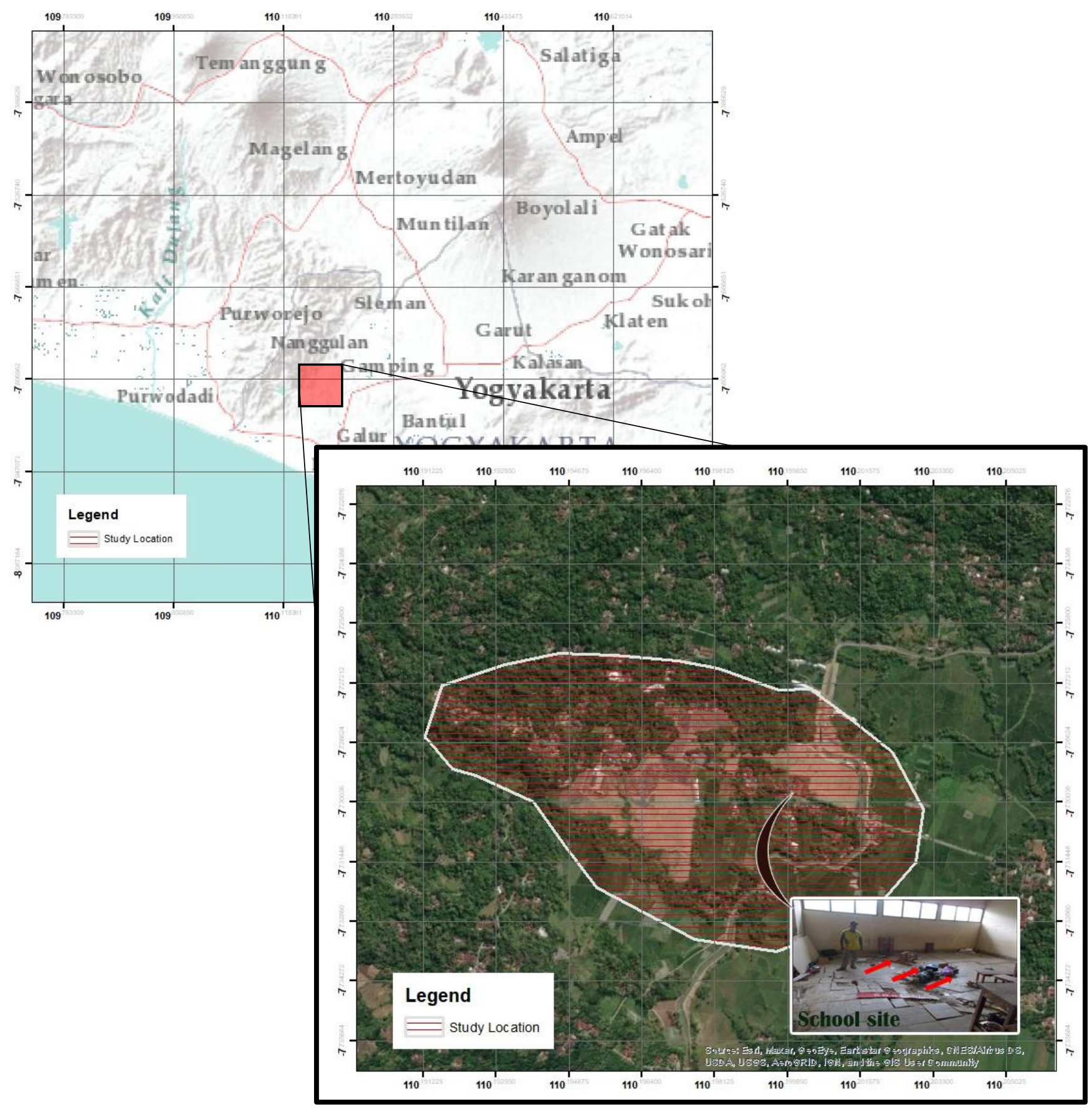

Figure 1 the study location map and the study location in Kalibawang at KulonProgo Regency, Special Region of Yogyakarta.

The use of SAR satellites is growing up in the past couple of decades, especially in monitoring surface movement. One method for the deformation measurement is to use the Interferogram Synthetic Aperture Radar (InSAR). Interferometric SAR (InSAR) is a combination of two or more SAR images obtained at different times, determining the change of the position in the satellite line of sight (LOS) on an area[9]. InSAR is performed as pixel by pixel product of the reference image (master) times the complex conjugated secondary (slave) image.

The growth of SAR satellite divided SAR satellite into several different categories. Commonly, the SAR satellite uses $\mathrm{X}$ band, $\mathrm{C}$ band, and $\mathrm{L}$ band frequencies, where each frequency has its sensitivity. The illustration of the capability of each sensor is shown in Figure 3 . The $\mathrm{C}$ band and $\mathrm{L}$ band are commonly used for InSAR processing. Generally, the radar with an L-band wavelength provides greater penetration than C-band because of the longer wavelength[10]. While the C-Band sensor is more sensitive due to the shorter wavelength, thus the signal can not pass the canopy of the forest or vegetational area[11]. The relationship between the radar wavelength and radar sensitivity is shown in Figure 4. 
The SAR image contains several components like the flat-earth phase $\phi^{\text {flat }}$, topographic phase $\phi^{\text {topo }}$, atmospheric phase $\phi^{a t m}$, the orbital change $\phi^{\text {orbit }}$, and noise phase $\phi^{\text {noise }}$, as shown in Eq. 1. This component reduces the SAR image quality; therefore, it needs to be removed [12]. The first technique of InSAR was birth in 1989, developed by [13] with the Differential Interferogram SAR (DInSAR) method. The DInSAR method is a stack of two different complex images at different times in a similar place. This method was successfully detecting the ground surface movement in $\mathrm{mm}$ measurement. Even though this method successfully removed some SAR image components, this method has several limitations, especially for the temporal limitation[14, 15]. Therefore, some researchers improve this technique to create a new technique, like [16, 17]. [17] has developed a new thing called as STAMPS/MTI method. Basically, this method refers to the PS-InSAR method developed by [18, 19]. This method uses the persistent scatter technique of the image to get a better result. The PS-InSAR method has been widely used for monitoring, including for landslide deformation monitoring as well as [20-22]. Therefore, it possible to know the deformation rate of a location and mechanism of the landslide movement. However, this is still a substantial challenge regarding the applicability of radar data to landslide monitoring [23].

$\phi=\phi^{\text {flat }}+\phi^{\text {topo }}+\phi^{\text {disp }}+\phi^{\text {atm }}+\phi^{\text {orbit }}+\phi^{\text {noise }}$

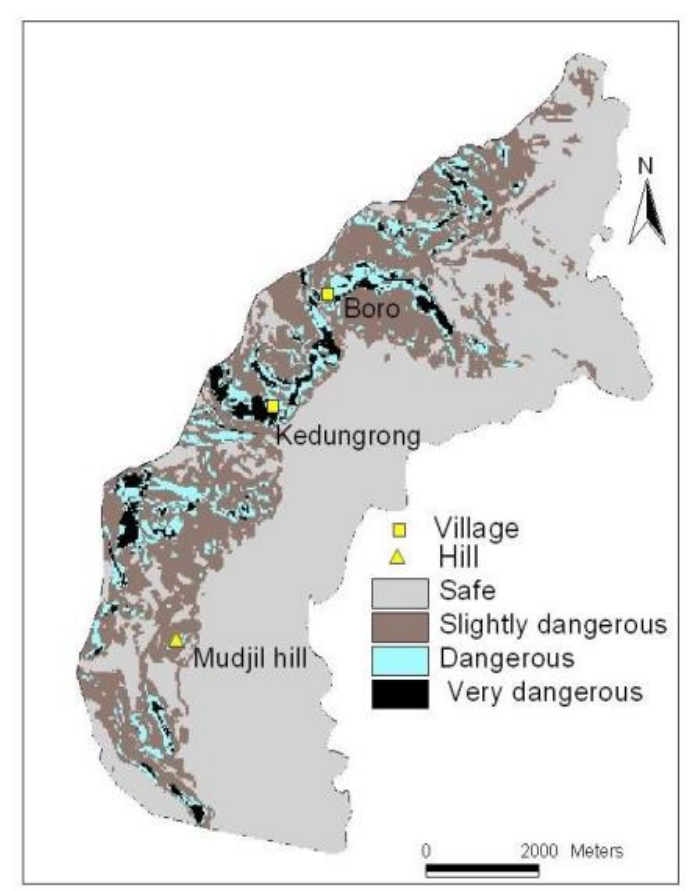

Figure 2 the landslide hazard map of the Kalibawang village published by [6].

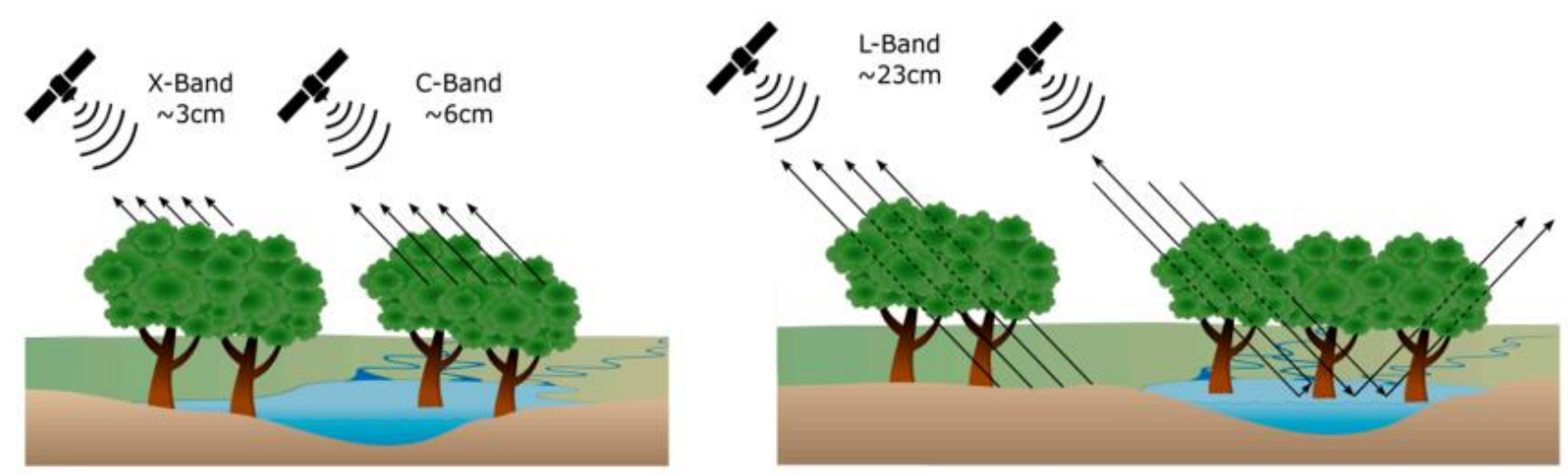

Figure 3 the illustration of each radar backscattering base on the wavelength capability [10]. 


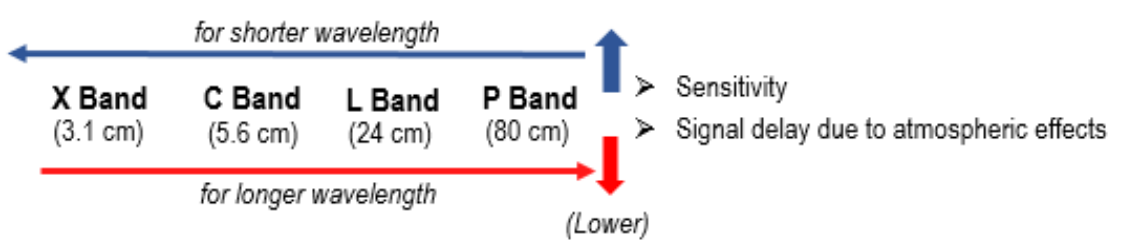

Figure 4 the relationship or the wavelength and sensitivity.

\section{METHODS}

The study was conducted using PS-InSAR analysis to determine the deformation of the location interest plotted on a base map. The movement of the slope is assumed due to rainfall that can cause a loss of soil strength. The correlation between rainfall data and PS-InSAR data is examined using a statistical approach such as correlation coefficient. Rainfall correlated with slope movement can be used to assessing and monitoring of landslide warning system.

\section{PS-InSAR Analysis}

The PS-InSAR method has been widely used for land subsidence and landslide monitoring. In this works, STAMPS/MTI was used. This method was developed [17] and a convenience method for PS-InSAR monitoring. In order to terrace the deformation rate of the location interest, the primary data for this analysis was using satellite data where those were gotten from Sentinel 1A satellite, and due to the slope face to the East direction, hence the ascending orbital was used.

We collected 27 complex images from January 2019 to December 2020. Those data were analyzed using three procedures: pre-processing step, main step, and mapping. At the first step, we used SNAP software developed by European Space Agency (ESA) and exported the result to the STAMPS/MTI method as the main processing. The STAMPS/MTI has several parameters that need to configure; this parameter may read in the STAMPS/MTI manual book. The final step is for plotting the result. The result was plotted using ArcMap software, where it was plotted on a base map.

\section{Rainfall Data}

Rainfall is assumed as the primary cause of the landslide. The rainfall may cause a loss of strength of the slope so that the movement possibly occurred. The rainfall data is obtained from the Tropical Rainfall Measuring Mission Precipitation Radar (TRMM) satellite product. Several studies regarding the validation of the TRMM were done by [24, 25], and [4]. The study showed that satellite-derived rainfall was over-predicted during the rainy season, and it has excellent agreement over the field rain gauge for the monsoonal rainfall type, as shown in Table 1. Therefore, the TRMM satellite might be used as a primary source for this study. The availability of the TRMM data only to the end of December 2019; thus, the continued data was using the Global Precipitation Measurement (GPM) satellite product. The study of [26] was shown the correlation of GPM data above 0.83; therefore, it possible to use in this work.

\section{Data Analysis}

The PS-InSAR data were compared to the rainfall data to know more about the land movement mechanism. Twenty-four months of the rainfall data are used, as shown in Figure 3. Based on the rainfall data, two characteristics of monsoon data were formed as usually as the tropical climate types, where the wet season formed since October to May and the dry season were formed since June to September [27]. The visualization was shown a similar pattern through rainfall and PS-InSAR data. In this work, these two kinds of data were examined by comparing the data using a statistical approach such as correlation coefficient to know the correlation between rainfall and PS-InSAR data. The formula of the correlation coefficient was given in Eq. 2.

The interpretation of the coefficient correlation was mentioned by [28-30], where there are two kinds of interpretation, positive correlation, and negative correlation. The formal rule the interpretation separated into three as shown in Table 1, namely (1) Weak correlation, (2) Moderate correlation, and (3) Strong correlation. Furthermore, the correlations are indicated by the p-value of the variable relationship, where statistically, the significant correlation is lower than 0.05. This P-value is known as alpha level or Sig. (2 tailed) in SPSS notation.

Table 1 the interpretation of coefficient correlation [28-30].

\begin{tabular}{ccc}
\hline Weak & Moderate & Strong \\
\hline$-0.5-0.5$ & Either -0.8 to -0.5 or 0.5 & Either $\geq 0.8$ or $\leq-0.8$ \\
& to 0.8 & \\
\hline
\end{tabular}


Table 2 the correlation of the TRMM satellite data with observed rainfall data [4, 26].

\begin{tabular}{lcc}
\hline & TRMM & GPM \\
\hline Correlation Coefficient & 0.831 & 0.86 \\
\hline RMSE (mm/day) & 149.619 & 71.76 \\
\hline
\end{tabular}

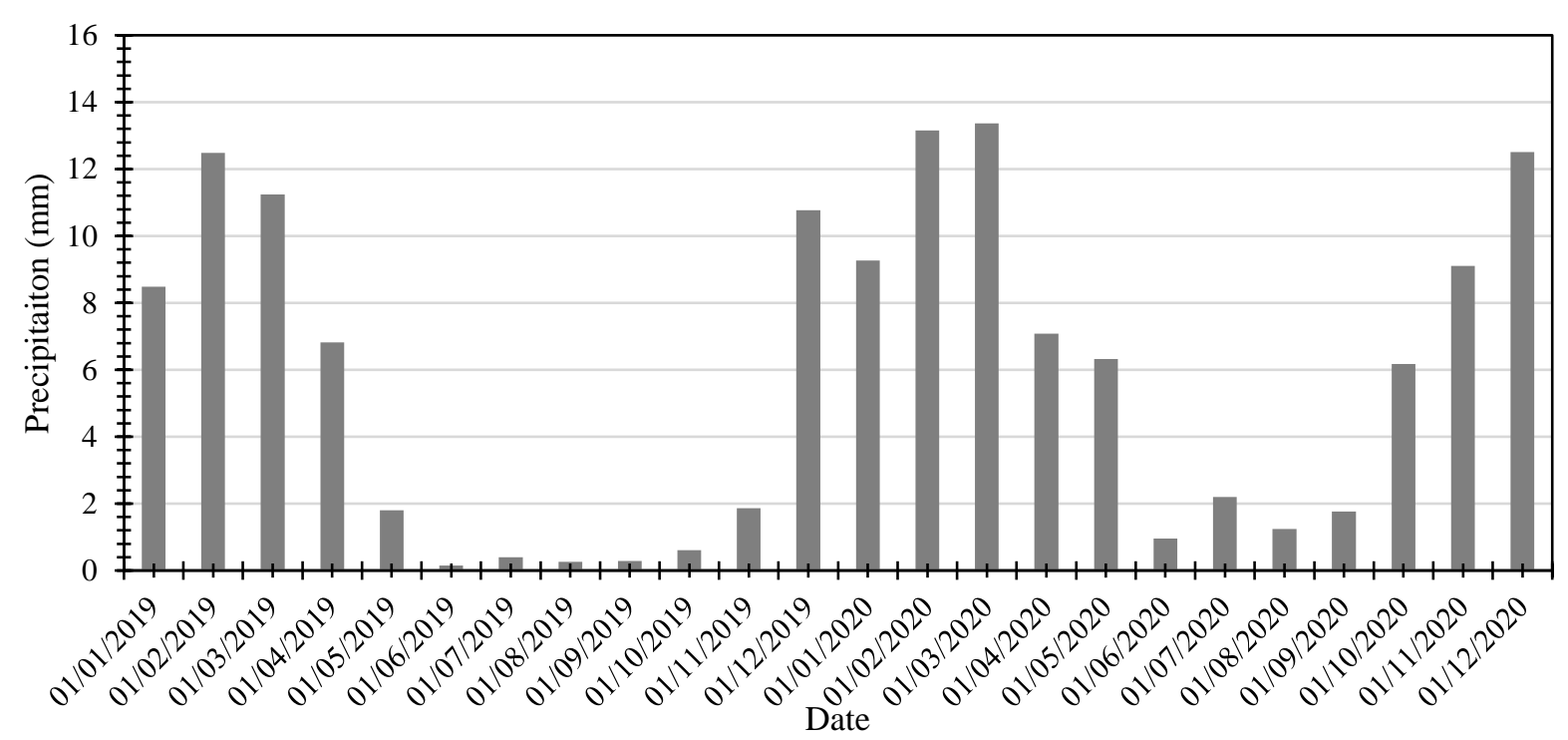

Figure 5 the visualization of the rainfall data.

$$
M=\frac{\sum_{i=1}^{n}\left(I_{i}-\bar{I}\right)\left(R_{i}-\bar{R}\right)}{\sqrt{\sum_{i=1}^{n}\left(I_{i}-\bar{I}\right)^{2} \sqrt{\sum_{i=1}^{n}\left(R_{i}-\bar{R}\right)^{2}}}}
$$

Where, $\mathrm{M}=$ Correlation coefficient of the movement, $\mathrm{I}=\mathrm{InSAR}$ Result, $\mathrm{R}=$ Rainfall Data.

\section{RESULTS AND DISCUSSIONS}

\section{Result Analysis}

Several data were analyzed and visualized. The visualization of the result shows that there is a movement during a couple of years. Figure 4 shows the maximum displacement rate is $>-23 \mathrm{~mm} /$ year and the minimum displacement is approximate to $5 \mathrm{~mm} /$ year, respectively, along the Line of Sight of the satellite direction. In this works, we chose three main points to know more about the mechanism of the movement; they are Loc 1 , Loc 2 , and Loc 3, respectively. Figure 5 shows the movement mechanism and the comparison between the displacement of the landslide area with the rainfall. The chart indicates a pattern of movement during a couple of years compared to the rainfall pattern.

We have examined the correlation between the rainfall and the PS-InSAR data using Statistical Product and Service Solutions (SPSS) software with the bivariate analysis of Pearson coefficient and correlation. The coefficient correlation result was shown in Table 2. The result shows the values of Loc 1, Loc 2, and Loc. 3 are 0.629, 0.623, and 0.585 , respectively. All of the results show the positive correlation where it has more than 0.5 so that it can be concluded that all locations correlate between displacement and precipitation. Therefore, it needs to know more about the cause of the movement. However, based on the displacement rate, it is categorized as the slow-landslide movement that the acceleration may increase as following years. Hence the mitigation of the further risk is needed. 


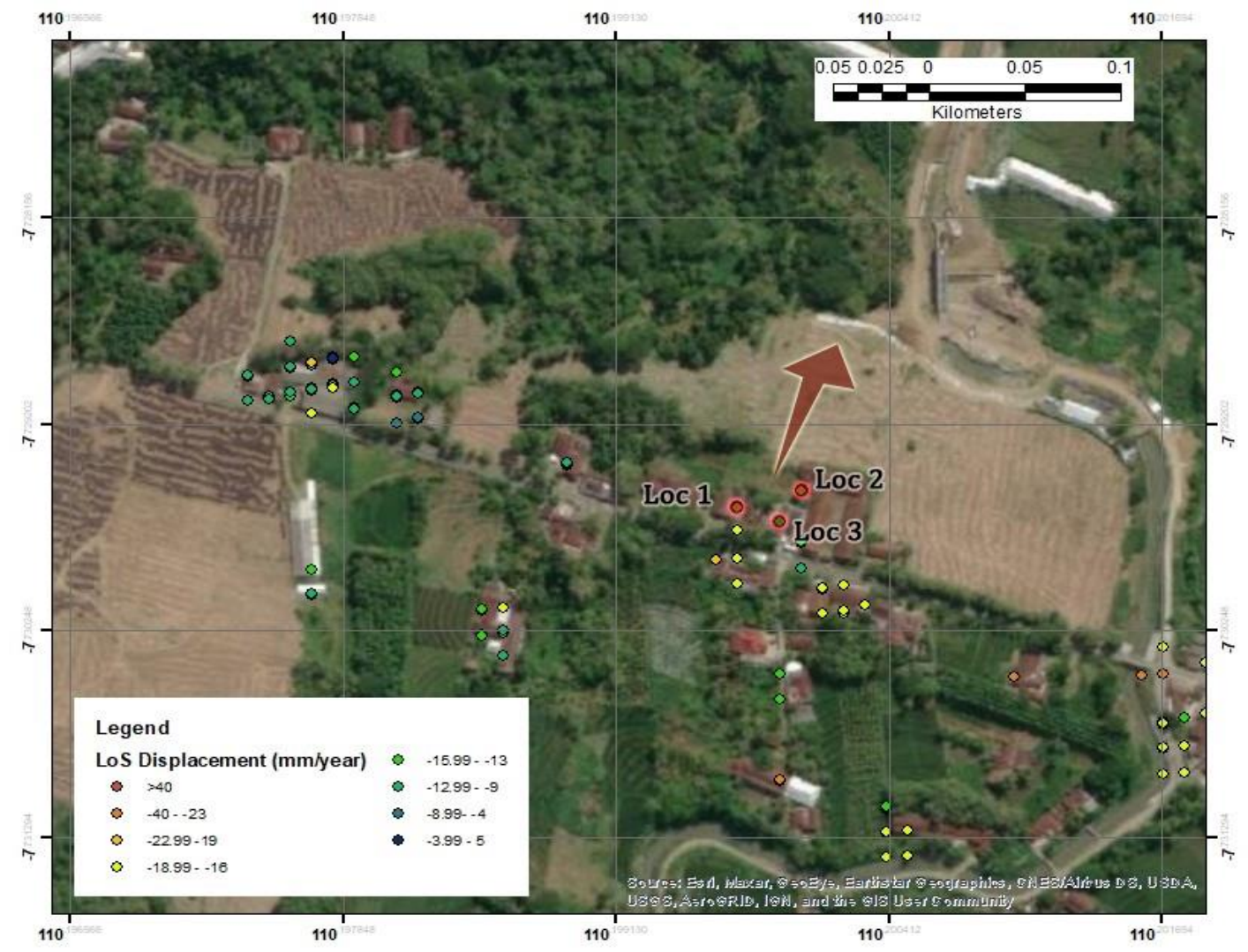

Figure 6 the visualization of PS-InSAR analysis along the LOS direction.

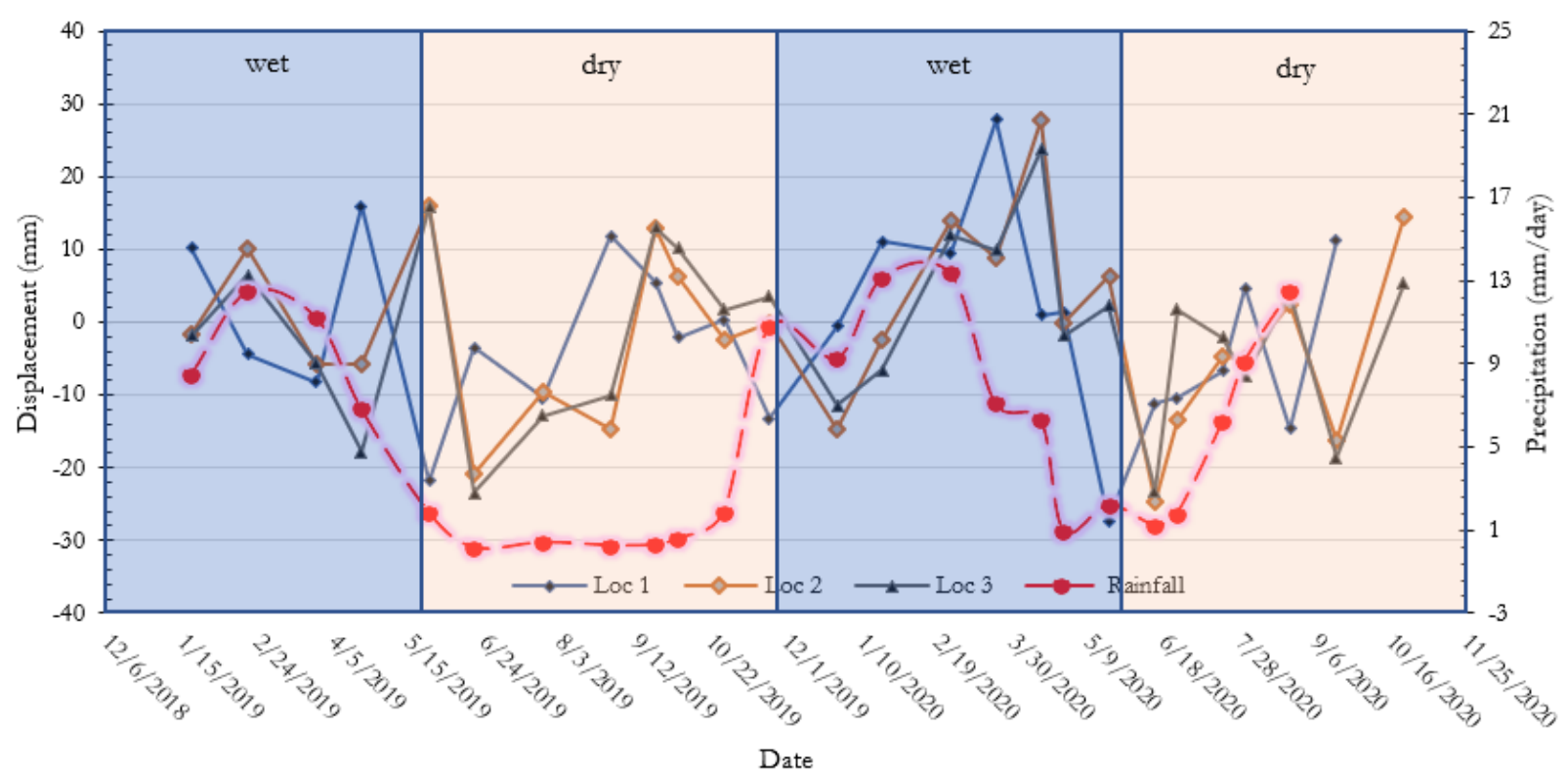

Figure 7 the comparison between the displacement with the precipitation during the time period.

Table 2 the SPSS output of the coefficient correlation of the rainfall against location interest Correlations

\begin{tabular}{clccc}
\hline & & PS_InSAR_Loc_1 & PS_InSAR_Loc_2 & PS_InSAR_Loc_3 \\
\hline Rainfall & Pearson Correlation & $.629^{* *}$ & $.623^{* *}$ & $.585^{* *}$ \\
\hline & Sig. (2-tailed) & 0.001 & 0.001 & 0.003 \\
\hline N & 24 & 24 & 24 \\
\hline
\end{tabular}

Correlation is significant at the 0.01 level (2-tailed). 


\section{DISCUSSION}

The use of remote sensing technology for landslide monitoring has been applied in this study, starting from the data acquisition like rainfall data to the data analysis, like PS-InSAR method, whether the application of InSAR for long-term or short-term is debatable. Figure 7 shows the rainfall tren and the PS-InSAR tren seem to have a pattern during wet and dry seasons, indicating a soil creep movement. Soil creep is the extremely slow movement of surficial soil layers on a slope (typically less than $1 \mathrm{~m}$ deep) induced by periodic volume changes due to climate change (wetting and drying) [31].

One of them is from the book chapter written by [32], where explained that creep is rarely realized because its movement is very slow. One of the influential factors is adding or reducing of the volume change during the wetting and drying process. In other words, it is triggered by water also. As a result, the creep is seasonal also. A similar issue was also discovered by [33], showing that during the wet season, the velocity of this form of creep may increase or be seen clearly, and likewise during the dry season. Therefore, the long-term monitoring to observe its movement was carried out by [34]. The method is simple, combining the PS-InSAR monitoring with in situ monitoring for several years in a row, and the trend is clear.

\section{CONCLUSIONS}

The conclusion is that rain can be considered one of the shift triggers. However, the correlation is moderate or in other words, it is not significant enough due to several other factors must be known first, such as the slope properties, the position of the water table, the type of soil, etc. Even so, it is still worth paying attention to for disaster mitigation, especially during the rainy season. First, because creep can be categorized as a slow-landslide movemen that the velocity is higher during rainy season. Second, because the slow-landslide movement is a destroyer that is rarely realized, the acceleration can increase over time. This paper may be an opening for further investigation and as a disaster mitigation to reduce the risk. This research is exciting if the availability of field data supports on it, and indeed many other locations have the same incident. However, it could be mismanaged because they do not understand the mechanism.

\section{ACKNOWLEGDEMENT}

We thank Prof. Ir. Agus S. Muntohar, Ph.D(Eng.) for his advice in this work during the modelling step., so we get more knowledge about landslide mechanism.

\section{REFERENCES}

[1] Muntohar AS, Ikhsan J, Liao HJ. Influence of Rainfall Patterns on the Instability of Slopes. Civil Engineering Dimension. 2013;15(2).

[2] Muntohar AS, Ikhsan J, Soebowo E, editors. Mechanism of rainfall triggering landslides in Kulonprogo, Indonesia. Geo-Congress 2013 2013; San Diego, California: Geotechnical Special Publication.

[3] Pramusandi S, Rifa'i A, Suryolelono KB. Determination of Unsaturated Soil Properties and Slope Deformation Analysis Due to the Effect of Varies Rainfall. Procedia Engineering. 2015;125:376-82.

[4] Chikalamo EE, Mavrouli OC, Ettema J, van Westen CJ, Muntohar AS, Mustofa A. Satellite-derived rainfall thresholds for landslide early warning in Bogowonto Catchment, Central Java, Indonesia. International Journal of Applied Earth Observation and Geoinformation. 2020;89.

[5] Subiyanti H, Rifa'i A, Jayadi R. Analisis Kelongsoran Lereng Akibat Pengaruh Tekanan Air Pori di Saluran Induk Kalibawang Kulonprogo. JURNAL ILMIAH SEMESTA TEKNIKA. 2011;14(1):15-25.

[6] Kyi SS, Nguyen TD, Aoki K, Mito Y, Suryolelono KB, Karnawati D, et al. Landslide risk microzonation by using multivariate statistical analysis and GIS. International Journal of JCRM. 2007;3(1):7-15.

[7] Zhang L, Sun Q, Hu J. Potential of TCPInSAR in Monitoring Linear Infrastructure with a Small Dataset of SAR Images: Application of the Donghai Bridge, China. Applied Sciences. 2018;8(3):425.

[8] Zhang Y, Meng XM, Dijkstra TA, Jordan CJ, Chen G, Zeng RQ, et al. Forecasting the magnitude of potential landslides based on InSAR techniques. Remote Sensing of Environment. 2020;241:111738.

[9] Ruiz-Armenteros AM, Bakon M, Lazecky M, Delgado JM, Sousa JJ, Perissin D, et al. Multi-Temporal InSAR Processing Comparison in Presence of High Topography. Procedia Computer Science. 2016;100:1181-90.

[10] Ottinger M, Kuenzer C. Spaceborne L-Band Synthetic Aperture Radar Data for Geoscientific Analyses in Coastal Land Applications: A Review. Remote Sensing. 2020;12(14).

[11] Townsend PA. Estimating forest structure in wetlands using multitemporal SAR. Remote Sensing of Environment. 2002;79:288-304.

[12] Hein A. Processing of SAR Data_ Fundamentals, Signal Processing, Interferometry. Heidelberg: SpringerVerlag Berlin Heidelberg; 2004.

[13] Gabriel AK, Goldstein RM, Zebker HA. Mapping small elevation changes over large areas: Differential radar interferometry. Journal of Geophysical Research. 1989;94(B7). 
[14] Lanari R, Casu F, Manzo M, Zeni G, Berardino P, Manunta M, et al. An Overview of the Small BAseline Subset Algorithm: a DInSAR Technique for Surface Deformation Analysis. Pure and Applied Geophysics. 2007;164(4):637-61.

[15] Bayer B, Simoni A, Schmidt D, Bertello L. Using advanced InSAR techniques to monitor landslide deformations induced by tunneling in the Northern Apennines, Italy. Engineering Geology. 2017;226:20-32.

[16] Hooper A, Segall P, Zebker H. Persistent scatterer interferometric synthetic aperture radar for crustal deformation analysis, with application to Volcán Alcedo, Galápagos. Journal of Geophysical Research. 2007;112(B7).

[17] Hooper A, Zebker H, Segall P, Kampes B. A new method for measuring deformation on volcanoes and other natural terrains using InSAR persistent scatterers. Geophysical Research Letters. 2004;31(23).

[18] Ferretti A, Prati C, Rocca F. Permanent scatterers in SAR interferometry. IEEE Transactions on Geoscience and Remote Sensing. 2001;39(1):8-20.

[19] Ferretti A, Prati C, Rocca F. Permanent Scatterers in SAR Interferometry. IEEE Geoscience and Remote Sensing Magazine. 1999.

[20] Wasowski J, Bovenga F. Investigating landslides and unstable slopes with satellite Multi Temporal Interferometry: Current issues and future perspectives. Engineering Geology. 2014;174:103-38.

[21] Intrieri E, Raspini F, Fumagalli A, Lu P, Del Conte S, Farina P, et al. The Maoxian landslide as seen from space: detecting precursors of failure with Sentinel-1 data. Landslides. 2017;15(1):123-33.

[22] Carlà T, Tofani V, Lombardi L, Raspini F, Bianchini S, Bertolo D, et al. Combination of GNSS, satellite InSAR, and GBInSAR remote sensing monitoring to improve the understanding of a large landslide in high alpine environment. Geomorphology. 2019;335:62-75.

[23] Colesanti C, Wasowski J. Investigating landslides with space-borne Synthetic Aperture Radar (SAR) interferometry. Engineering Geology. 2006;88(3-4):173-99.

[24] Mantas VM, Liu Z, Caro C, Pereira AJSC. Validation of TRMM multi-satellite precipitation analysis (TMPA) products in the Peruvian Andes. Atmospheric Research. 2015;163:132-45.

[25] Fakhuroyan, Wati T, Sukmana A, Kurniawan R. Validation of Satellite Daily Rainfall Estimates Over Indonesia. Indonesia Journal of Spatial and Regional Analysis. 2018;31(2):170-80.

[26] Santos LOF, Querino CAS, Querino JKAS, Junior ALP, Moura ARMM, Machado NG, et al. Validation of rainfall data estimated by GPM satellite on Southern Amazon region. Ambiente e Agua - An Interdisciplinary Journal of Applied Science. 2018.

[27] Ngadisih, Samodra G, Bhandary NP, Yatabe R. Landslide Inventory: Challenge for Landslide Hazard Assessment in Indonesia. GIS Landslide2017. p. 135-59.

[28] Devore JL. Probability and Statistics for Engineering and the Sciences: Cengage Learning; 2011.

[29] Moore DS, Notz WI, Fligner MA. The Basic Practice of Statistics. New York: W. H. Freeman; 2017.

[30] Boslaugh S, Watters P. Statistics in a Nutshell English Edition. Gravenstein Highway North, Sebastopol: O’Reilly Media, Inc.; 2008.

[31] Hungr O, Leroueil S, Picarelli L. The Varnes classification of landslide types, an update. Landslides. 2013;11(2):167-94.

[32] Terzaghi K, Paige S. Mechanism of Landslides. Application of Geology to Engineering Practice: Geological Society of America; 1950. p. 0.

[33] Wasowski J, Gostelow P. Engineering Geology Landslide Investigations and SAR Interferometry. 1999.

[34] Wasowski J, Pisano L. Long-term InSAR, borehole inclinometer, and rainfall records provide insight into the mechanism and activity patterns of an extremely slow urbanized landslide. Landslides. 2019;17(2):445-57. 